\title{
Relationship Between the Texture and Young's modulus over the Section of Cold-rolled Rods of Low-modulus Biocompatible Alloy
}

\section{Grib S.V. ${ }^{1}$, Ivasishin O.M. ${ }^{2}$, Illarionov A.G. ${ }^{1,3}$, and Karabanalov M.S.}

${ }^{1}$ Ural Federal University named after the first President of Russia B.N. Yeltsin, Russian Federation

${ }^{2}$ G.V. Kurdyumov Institute for the Physics of Metals of the National Academy of Sciences of Ukraine, Ukraine

${ }^{3}$ M.N. Miheev Institute of Metal Physics of Ural Branch of Russian Academy of Sciences, $18 \mathrm{~S}$. Kovalevskaya Street, Yekaterinburg, Russia, 620137

\section{Abstract}

The influence of the texture type on the Young's modulus value in the different sections of cold-deformed rods of Zr-31Ti-18Nb alloy (IMP BAZALM) was studied. It was found, an increase in the compression deformation degree from 63 to $84 \%$ of Zr-31Ti-18Nb alloy

Corresponding Author:

Grib S.V.

s.v.grib@urfu.ru

Received: 25 February 2019

Accepted: 9 April 2019

Published: 15 April 2019

Publishing services provided by Knowledge E

(c) Grib S.V. et al. This article is distributed under the terms of the Creative Commons

Attribution License, which permits unrestricted use and redistribution provided that the original author and source are credited.

Selection and Peer-review under the responsibility of The Ural school-seminar of metal scientists-young researchers Conference Committee.

\section{G OPEN ACCESS} during cold rolling contributed to the improvement of $\{001\}<110>$ deformation cube texture. This contributed to the preferential orientation of the directions $<001>$ and $<110>$ parallel to ND and RD (TD) directions, accordingly. The minimum values of the Young's modulus were typical for areas where low-module $<001>$ orientation prevailed, and the maximum values of the Young's modulus were characteristic for areas with high-modules $<110>$ orientations. So, in the alloy deformed by $84 \%$, the lowest values of the Young's modulus were obtain in the rolling plane up to $53 \mathrm{GPa}$, and the highest values in plane perpendicular to the rolling direction up to $70 \mathrm{GPa}$.

Keywords: Zr-Ti-Nb system, biocompatible alloy, Young's modulus, texture.

\section{Intorduction}

The IMP BAZALM alloy of the Zr-Ti-Nb system based on the metastable $\beta$-solid solution was studied in this work. The alloy has a low Young's modulus (55-70 GPa) and was developed as a biocompatible material [1, 2]. In [1] was shown the use of lowtemperature thermomechanical processing of the alloy allows to obtain rods with a tensile Young's modulus at the level of $47 \mathrm{GPa}$ and high values of reversible deformation (up to $2,83 \%$ ). According to [3], the texture is formed in the IMP BAFZALM alloy quenched on metastable $\beta$-solid solution during cold deformation and is known contributes to obtain anisotropic properties in the material, including the Young's modulus in the Ti$\mathrm{Nb}-\mathrm{Zr}$ system [4]. In addition, the textural state can change over the cross section of 
cold-deformed alloys [5], also leading to a certain change in the physicomechanical characteristics depending on their measurement at a specific section location [6]. However, such studies on the IMP BAZALM alloy have not been carried out before. On this basis, the purpose of the work was to study the influence of the texture type of different sections of cold-deformed IMP BAZALM alloy rods on the Young's modulus value.

\section{Material and Methods}

The material for the study was IMP BAFZALM alloy (Zr-31Ti-18Nb at. \%) quenched on a metastable $\beta$-solid solution in the form of two cold-rolled rods of square section $(4.3 \times 4.3$ and $2.87 \times 2.87 \mathrm{~mm}^{2}$ ), obtained from the $8 \mathrm{~mm}$ diameter rod. The compression deformation degree was 63 and $84 \%$ for $4.3 \times 4.3$ and $2.87 \times 2.87 \mathrm{~mm}^{2}$ rods accordingly. The rods were cut across and along the rolling direction to analyze the anisotropy of properties with depend on the direction of measurement, and then the Young's modulus was measured by microindentation using a CSM Instruments device with a load of $9 \mathrm{H}$ and $0.25 \mathrm{~mm}$ measurement step as it shown in the Fig. 1.

The structure and phase composition analysis of the rods was carried out by optical microscopy and X-ray diffraction phase analysis (XRD) using an placeOlympus microscope and a Bruker D8 Advance diffractometer accordingly. Evaluation of the texture state over the cross section of the studied rods was performed using an EBSD attachment to the scanning electron microscope Zeiss Auriga with accelerating voltage 20 kV.

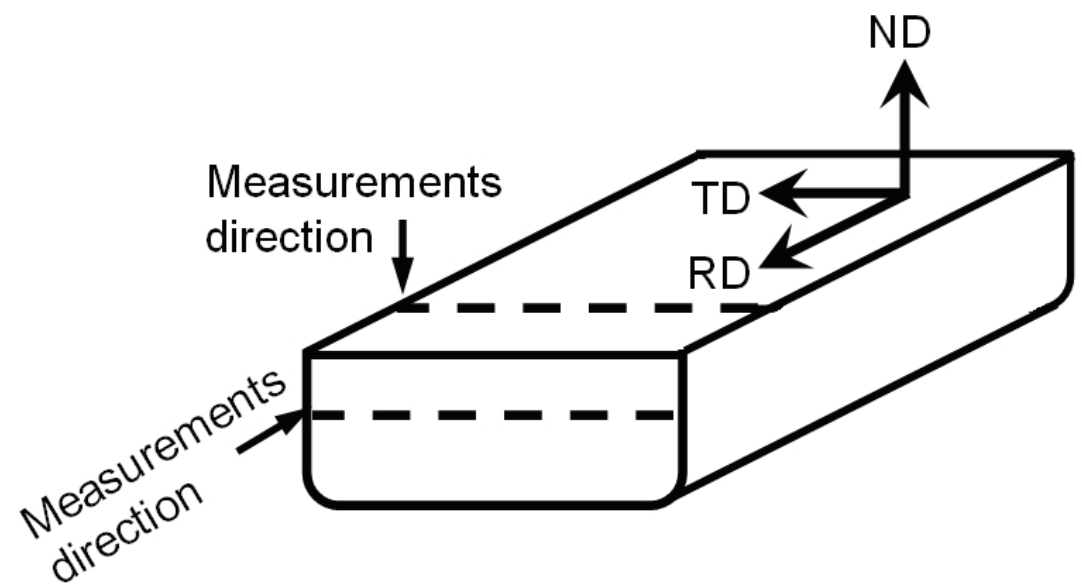

Figure 1: The Young's modulus measurements scheme of the deformed alloy IMP-BAZALM (the dotted line is the line along which measurements were made) ND - normal direction; RD - rolling direction; TD transverse direction. 


\section{Results and Discussion}

The microstructure of cold-rolled rods of square section $4.3 \times 4.3$ and $2.87 \times 2.87 \mathrm{~mm}^{2}$ in longitudinal and cross-section is presented in Fig. 2.

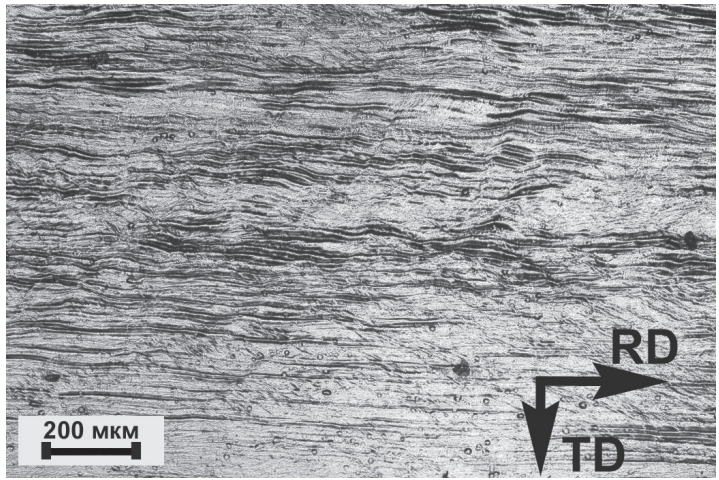

a

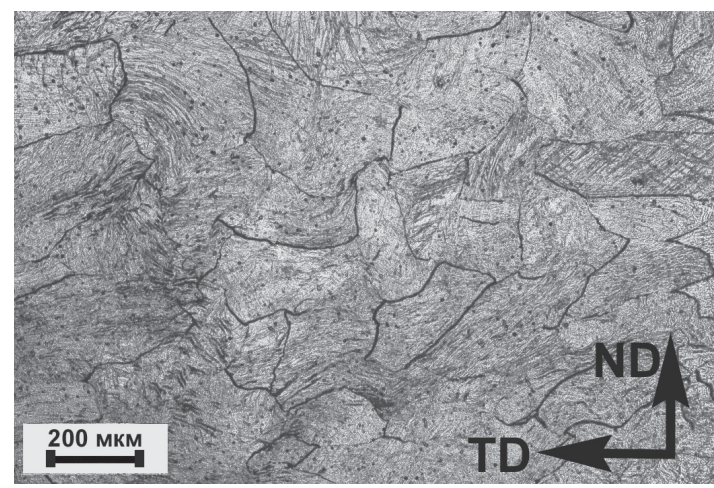

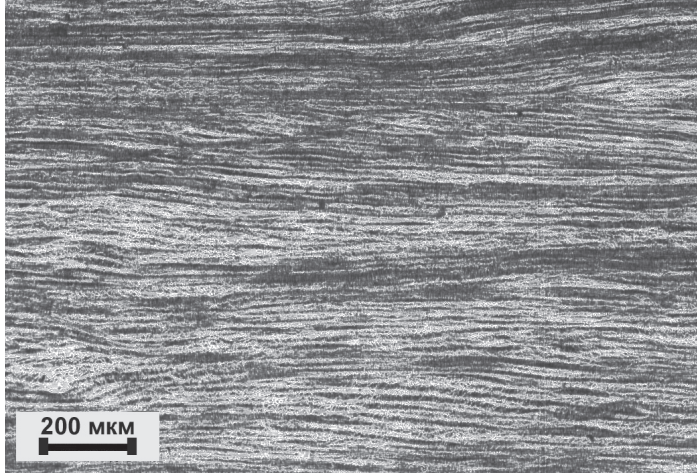

b

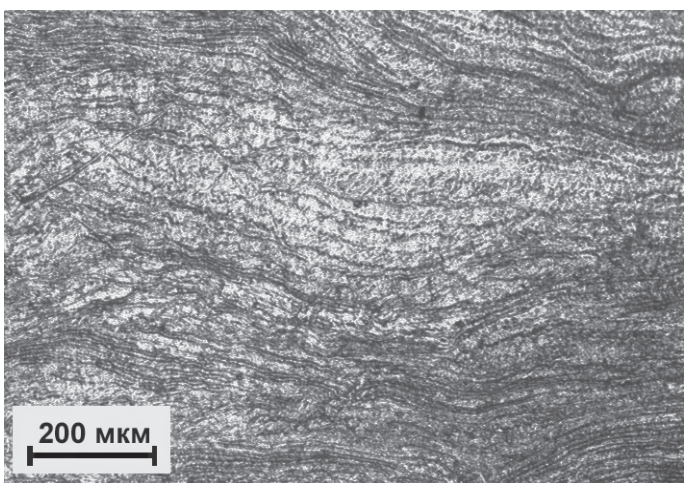

$\mathrm{d}$

Figure 2: Microstructure of $4.3 \times 4.3$ and $2.87 \times 2.87 \mathrm{~mm}^{2}$ rods in the longitudinal $(\mathrm{a}, \mathrm{b})$ and transverse $(\mathrm{c}, \mathrm{d})$ section.

Analysis of the structure showed that with increasing of the compression deformation degree from $63 \%\left(4.3 \times 4.3 \mathrm{~mm}^{2}\right.$ rod $)$ to $84 \%\left(2.87 \times 2.87 \mathrm{~mm}^{2}\right.$ rod $)$ the microstructure accepted characteristic fibrous structure owing to regular stretching of grains along the rolling direction and flattening in height in the cross section (Fig. 2). If after deformation $63 \%$ in the cross section, it is possible to clearly separate the boundaries of individual grains, then after deformation $84 \%$ it is difficult to do.

XRD data (Fig. 3) showed the alloy is on the $\beta$-solid solution state after cold rolling there are only diffraction peaks of $\beta$-phase on the X-ray diffraction patterns. Based on inverse pole figures (IPF) for the $4.3 \times 4.3 \mathrm{~mm}^{2}$ rods obtained by the EBSD method (Fig. 4) one can observe that [100] crystallographic direction is most likely parallel to sample normal direction (ND) and in the case of RD (rolling direction) and TD (transverse direction) directions most intense has [110] crystallographic direction. It can be concluded, 
$\{001\}<110>$ deformation cube texture typical for deformed alloys with body-centered cubic lattice (bcc) is formed in the rod [7]. The cubic lattice orientation relative to ND, RD and TD directions in the deformed alloy is shown in Fig. 5.

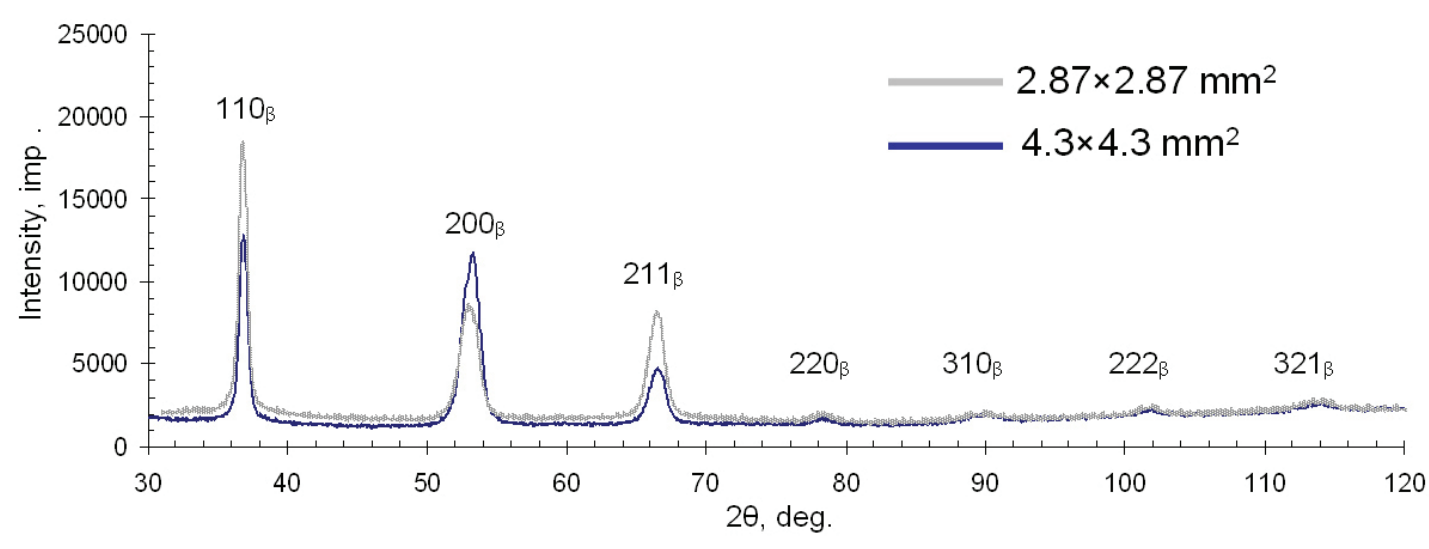

Figure 3: X-ray spectra's obtained from cross-section of $4.3 \times 4.3$ and $2.87 \times 2.87 \mathrm{~mm}^{2}$ rods.
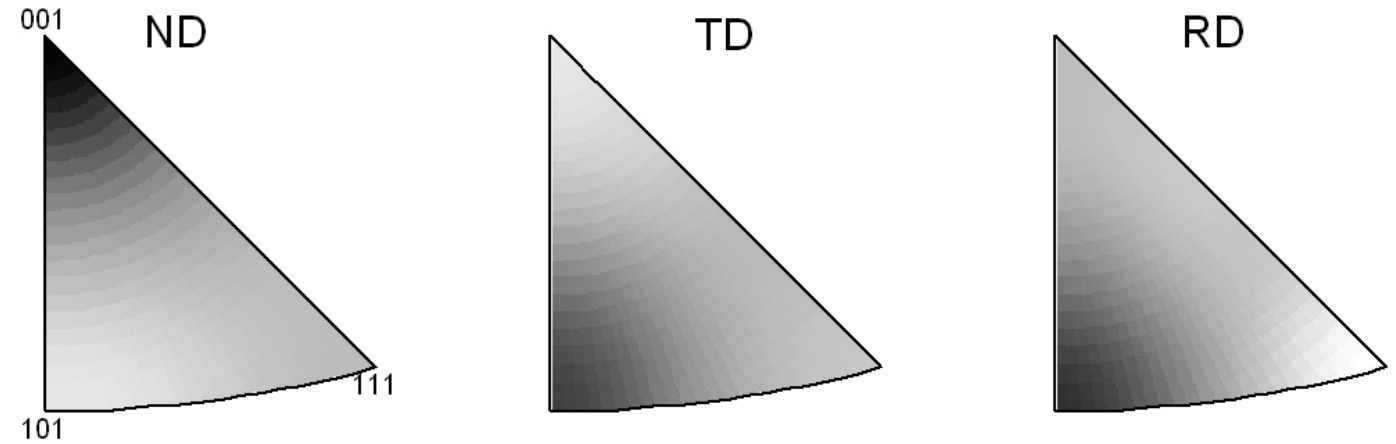

Figure 4: Inverse pole figures obtained from the cross section of the $4.3 \times 4.3 \mathrm{~mm}^{2}$ rod.

Comparative analysis of XRD (Fig. 3) and EBSD data (Fig. 4) shown that increasing the compression deformation degree from the $4.3 \times 4.3 \mathrm{~mm}^{2}$ to the $2.87 \times 2.87 \mathrm{~mm}^{2}$ rod contributed enhancing $\{001\}<110>$ deformation cube texture. This conclusion is based on comparison of X-ray spectra's of different sections rods. In comparison with the $\mathrm{X}$ ray spectra $4.3 \times 4.3 \mathrm{~mm}^{2}$ rod, the noticeable decrease in the intensity of the peak 200 (approximately 1.5-2 times) with a corresponding increase in the intensity of the 110 peak (about the same 1.5-2 times) is detected on the X-ray spectra $2.87 \times 2.87 \mathrm{~mm}^{2}$ rod. This effect is realized when the texture $\{001\}<110\rangle$ is enhanced, since in this case the component due to $\{110\}$ planes is increased and component due to $\{100\}$ planes is decreased, which is observed.

The data of the Young's modulus change and the orientation of crystallites over the cross section of rods (the axis "distance") are shown in Fig. 6. 


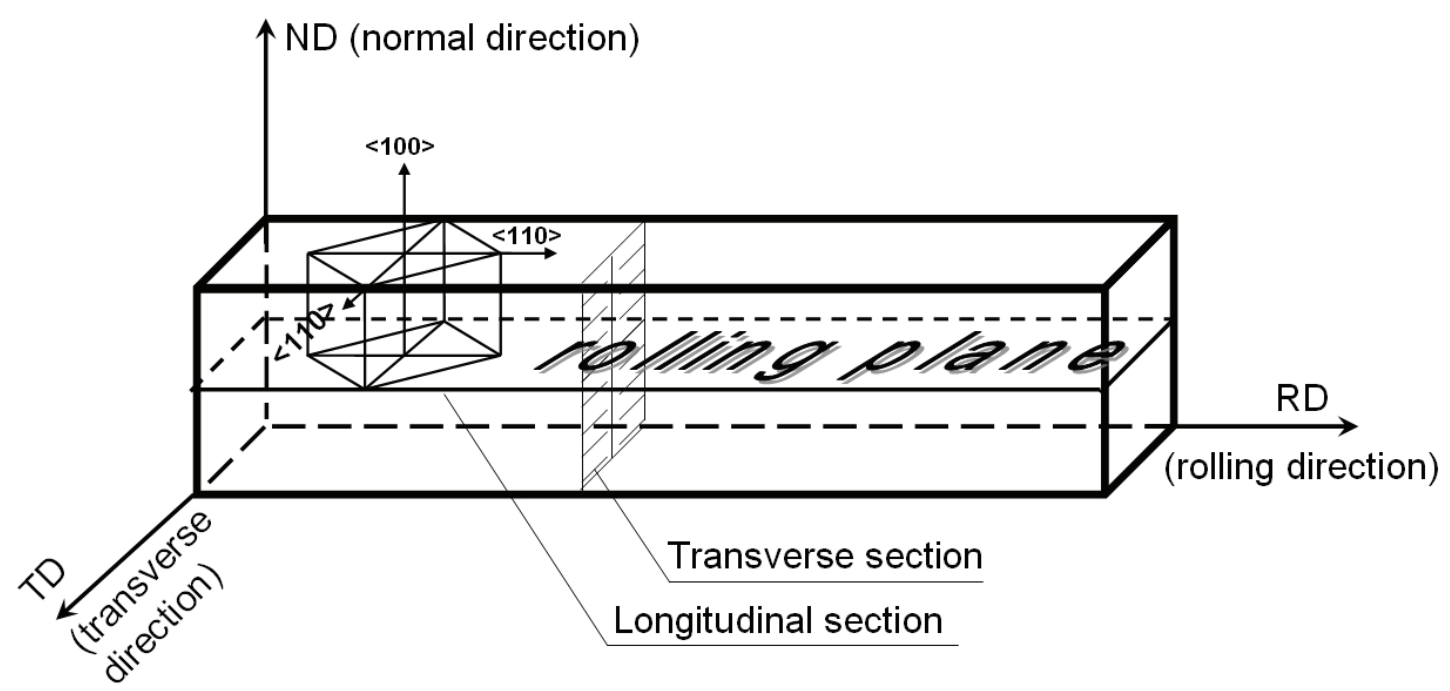

Figure 5: The cubic lattice orientation relative to ND, RD and TD directions in the deformed alloy (the scheme).

Most of Young's modulus values, measured at the approximately equal distances from the edge of the rod, are smaller in the rolling plane than in the plane perpendicular to the rolling direction and this effect is especially enhanced in the smaller cross-section rod (Fig. 6 a, b). The obtained regularity agrees well with the results of XRD and EBSD data (Fig. 3,4$)$ : the texture $\{001\}<110>$ increases with an increase in the compression deformation degree. This contributed to the preferential orientation of the directions $<001>$ and $<110>$ along the directions of the Young's modulus measurements in the rolling plane and in the plane perpendicular to the rolling direction, respectively. According to [4], the $\langle 001\rangle$ direction is low-module compared to $\langle 110\rangle$, which is confirmed by the present studies. So, the comparison of the obtained Young's modulus values and the preferential orientations at the measurement sites showed a good correlation between them, both for a $4.3 \times 4.3 \mathrm{~mm}^{2}$ and $2.87 \times 2.87 \mathrm{~mm}^{2}$ rods (Fig. $6 \mathrm{a}$, b). The minimum values of the Young's modulus were typical for areas where low-module $<001>$ orientation prevailed, and the maximum values of the Young's modulus were characteristic for areas with high-modules $\langle 110\rangle,<111>$ orientations. It can also be noted that the formation of a more perfect texture in the rods with increasing deformation degree contributed to a more regular ("wavy") change in the Young's modulus over the rod cross-section with minima near the surface and center of the rod and maxima by $1 / 4$ and $3 / 4$ length of square section. Previously, a regular change of the Young's modulus values over the cross section of a cold-deformed rod was fixed in a copper wire $[5,6]$. It was due to a change in the intensity of the main orientations in the cross section, which is also observed in this case. 


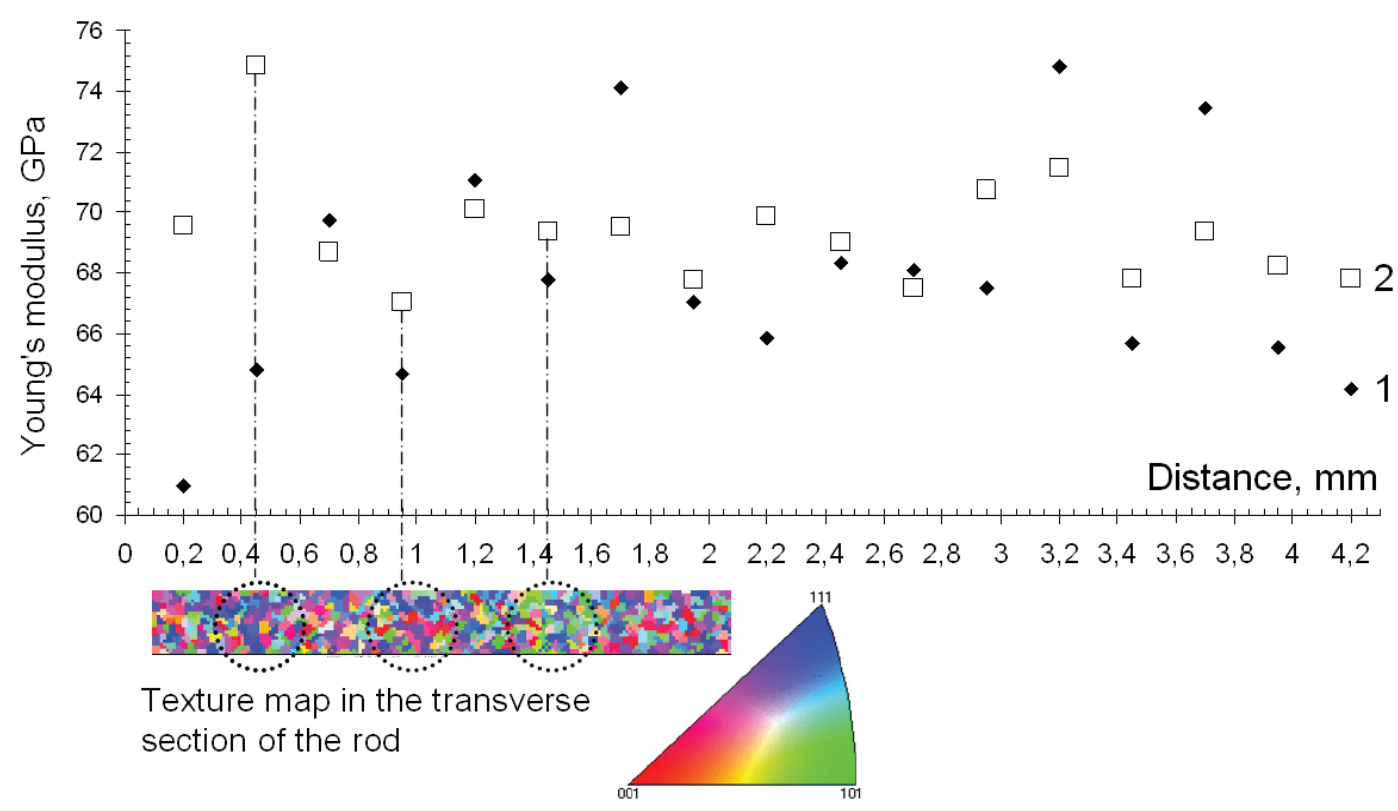

a

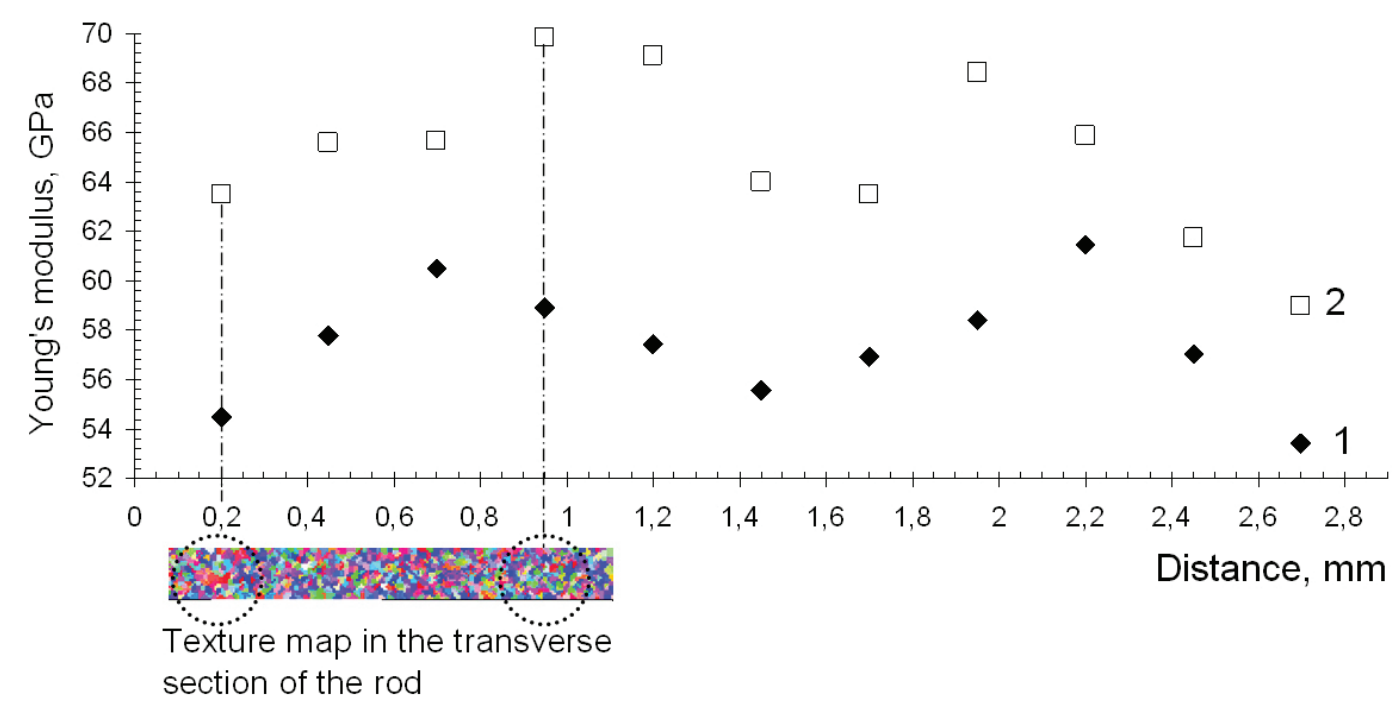

$\mathrm{b}$

Figure 6: The change of Young's modulus and preferential orientations of crystallites over the cross section of $4.3 \times 4.3$ (a) and $2.87 \times 2.87 \mathrm{~mm}^{2}$ (b) rods (1 - Values of Young's modulus obtained in the rolling plane; 2 values of Young's modulus obtained in the plane perpendicular to the direction of rolling).

In general, for the $4.3 \times 4.3 \mathrm{~mm}^{2}$ rod, the Young's modulus values varied from 61 to $75 \mathrm{GPa}$ (the difference is $14 \mathrm{GPa}$ ) in the rolling plane, and in the plane perpendicular to the rolling direction from 67 to $75 \mathrm{GPa}$ (the difference is $8 \mathrm{GPa}$ ). The average value of 67 and $69 \mathrm{GPa}$, accordingly. In the $2.87 \times 2.87 \mathrm{~mm}^{2}$ rod, the Young's modulus values varied from 53 to $62 \mathrm{GPa}$ (the difference is $9 \mathrm{GPa}$ ) in the rolling plane, and in the plane perpendicular to the rolling direction from 60 to $70 \mathrm{GPa}$ (the difference is $10 \mathrm{GPa}$ ). The average value of 58 and 66 GPa accordingly. It can be seen, the improvement of the 
texture also contributed to the increase in the difference in the magnitude of the Young's modulus in the rolling plane and the plane perpendicular to the rolling direction. That increased the anisotropy of the elastic properties.

\section{Summary}

Thus, based on the work done, the following conclusions can be drawn:

1. It is shown, an increase in the compression deformation degree of $\mathrm{Zr}-31 \mathrm{Ti}-18 \mathrm{Nb}$ alloy during cold rolling contributed to the improvement of $\{001\}<110>$ deformation cube texture.

2. It was found, the enhancing $\{001\}<110>$ deformation cube texture in the $2.87 \times 2.87 \mathrm{~mm}^{2}$ rod compared with $4.3 \times 4.3 \mathrm{~mm}^{2}$ rod leaded to an increase in the anisotropy of the Young's modulus values measured in the rolling plane and in the plane perpendicular to the rolling direction; the lowest values of the Young's modulus were obtain in the rolling plane up to $53 \mathrm{GPa}$, and the highest values in plane perpendicular to the rolling direction up to $70 \mathrm{GPa}$.

3. The interrelation between the values of the Young's modulus, measured over the cross section of the rod, and the orientations of crystallites is established.

\section{Acknowledgements}

The study was funded by the grant of Russian Science Foundation (the project № 18-1300220).

The work was carried out using the laboratory equipment "Structural methods of analysis and properties of materials and nanomaterials" of the Center of Ural Federal University.

\section{References}

[1] I.O. Skyba, O.P. Karasevska, B.M. Mordyuk, P.E. Markovsky, V.M. Shyvanyuk, Effect of strain-induced $\beta \rightarrow \omega$ transformation on mechanical behaviour of $\beta$-titanium and $\beta$-zirconium alloys, Metallofizika i Noveishie Tekhnologii. 31(2009) 1573-1587.

[2] A.A. Popov, S.V. Grib, O.A. Elkina, O.M. Ivasishin, P.E. Markovskii, I.A. Skiba, Effect of heat treatment and plastic deformation on the structure and elastic modulus 
of a biocompatible alloy based on zirconium and titanium, Physics of Metals and Metallography. 113 (2012) 382-390.

[3] S.V. Grib, O.M. Ivasishin, A.G. Illarionov, A.A. Popov, Effect of cold plastic deformation on the structure and physicomechanical properties of a biocompatible alloy of the Zr-Ti-Nb system, Physics of Metals and Metallography. (2019). In print.

[4] Xing Wang, Ligang Zhang, Ziyi Guo, Yun Jiang, Xiaoma Tao, Libin Liu, Study of low-modulus biomedical $\beta$ Ti-Nb-Zr alloys based on single-crystal elastic constants modeling, Journal of the mechanical behavior of biomedical materials. 62 (2016) 310318.

[5] S.L. Demakov, A.G. Illarionov, M.A. Ivanova, Yu.N. Loginov, Forming texture at the manufacturing stage of copper wire, Cables and wires. 2 (2012) 8-13.

[6] P.P. Pal-Val, V.D. Natsik, L.N. Pal-Val, A.A. Davydenko, A.P. Rybalko, Yu.N. Loginov, S.L. Demakov, A.G. Illarionov, Unusual Young's modulus behavior in ultrafine-grained and microcrystalline copper wires caused by texture changes during processing and annealing, Materials Science and Engineering A. 618 (2014) 9-15.

[7] M. Tane, S. Akita, T. Nakano, K. Hagihara, Y. Umakoshi, M. Niinomi, \& H. Nakajima, Peculiar elastic behavior of $\mathrm{Ti}-\mathrm{Nb}-\mathrm{Ta}-\mathrm{Zr}$ single crystals, Acta. Mater. 56 (2008) 2856-2863. 